\title{
Staff experience and attitudes towards technology-enhanced learning initiatives in one Faculty of Health and Life Sciences
}

\author{
Peter Reed* \\ Institute for Learning \& Teaching, Faculty of Health \& Life Sciences, The University of \\ Liverpool, Liverpool, United Kingdom
}

(Received 6 September 2013; final version received 31 August 2014)

\begin{abstract}
Further to earlier work carried out by the student union (SU) along with strategic discussions regarding technology-enhanced learning (TEL), this research aimed to identify the attitudes and experience of teaching staff in relation to specific uses of technology in learning and teaching. Data obtained through an online questionnaire $(n=100)$ suggest that teaching staff are generally agreeable to the need for consistency in the virtual learning environment and identify specific criteria to be included within 'minimum standards'; have some experience and interest in solutions to enable online submission, marking and feedback; and whilst there is more resistance, there was still interest in the provision of recorded lectures. Respondents overwhelmingly identified lack of time as a significant barrier to engaging with TEL, as well as other factors such as lack of skills and support.
\end{abstract}

Keywords: attitudes; experience; TEL; minimum standards; lecture capture; online submission; e-marking

\section{Introduction}

The term 'technology-enhanced learning' (TEL) has emerged through suggestions that its predecessor 'e-Learning' was too narrow for the variety of uses of technology in learning and teaching (HEFCE 2009). The Higher Education Funding Council for England (HEFCE) identifies three levels where technology could enhance learning and teaching: Efficiency, Enhancement and Transformation (HEFCE 2009). This suggests that technology can make existing processes more effective in relation to cost, time, scalability or sustainability; improve or enhance existing processes/outcomes; or radically transform existing processes.

Kregor, Breslin, and Fountain (2012) suggest that the need to remain competitive in the HE marketplace means universities no longer have a choice with regards to implementing e-Learning strategies. Further to this, students are expecting and demanding effective use of technology to support and enhance their studies, as evidenced in a recent report produced by the student union in the institution under study (Bee 2013), and such expectations are impacting on National Student Survey (NSS) data (Reed and Watmough In press).

It is with such drivers in mind that universities are investing in TEL infrastructure and assessing its impact on learning, teaching and assessment. In a systematic review

*Corresponding author. Email: peter.jp.reed@gmail.com

Research in Learning Technology 2014. (C) 2014 P. Reed. Research in Learning Technology is the journal of the Association for Learning Technology (ALT), a UK-based professional and scholarly society and membership organisation. ALT is registered charity number 1063519 . http://www.alt.ac.uk/. This is an Open Access article distributed under the terms of the Creative Commons CC-BY 4.0 License (http:// creativecommons.org/licenses/by/4.0/), allowing third parties to copy and redistribute the material in any medium or format and to remix, transform, and build upon the material for any purpose, even commercially, provided the original work is properly cited and states its license. 
conducted by Kirkwood and Price (2013), almost 20\% of TEL interventions were used to replace existing teaching, 50\% were supplementary activities and around 30\% were associated with structural changes in teaching and learning. The authors go on to suggest the term 'TEL' is used too often and in an unconsidered manner, suggesting a real need to strategically consider not only the use of the term but also implementations related to the use of technology in learning and teaching. Strategies are seldom solutions in themselves, however, as Kregor, Breslin, and Fountain (2012) suggest:

The success of a university's e-learning strategy is ultimately in the hands of the users of the technologies implemented to achieve its goals: how deeply they embrace a suite of technologies will determine the impact it has. It is essential then, to understand these users and their relationship with technology in implementing a successful strategy. (p. 1382)

Furthermore, there are suggestions that the strong disciplinary focus amongst academics can 'inhibit acceptance of change' (Salmon, Jones, and Armellini 2008), and the most common barriers within the literature to engaging or innovating with technology is related to both time (Newton 2003; Reed 2012) and lack of reward structures in place for innovators (Attwell and Pumilia 2007; Charlesworth et al. 2007; Seonghee and Boryung 2008).

Salmon (2005) suggests the imperative on research outputs leaves few benefits for academics to innovate in teaching; a problem likely spiralled in research-intensive Russell Group Universities.

For others, a lack of skills/literacies can be a significant barrier. Kregor, Breslin, and Fountain (2012) report 32\% of respondents in their research were less than confident with the use of Information and Communication Technologies (ICTs) in learning and teaching. To this end, it is important to consider the support in place for these users to overcome barriers of time, skillsets and confidence in order for successful implementation. Potentially of equal importance are clear advantages to learning, teaching and assessment, as well as the significance they have in the 'grander scheme' rather than 'using technology for its own sake' (Kregor, Breslin, and Fountain 2012; Salmon 2005).

Of particular note in Kregor, Breslin, and Fountain (2012) was a difference between staff and student perception of the use of technology, whereby 'time saving and flexibility gains for students may inversely require additional workload or skill demands for some staff' (p. 1397). The authors suggest the contrasting views could be related to the differing roles, for example, academic staff as creators/developers/ producers, and students as users/consumers. Reed and Watmough (In press) also suggest this could be related to a misunderstanding of the importance of some aspects to students. These discussions provide an interesting paradox for this study.

\section{Literature review}

This research aimed to determine the attitudes of academic staff within one Faculty of Health and Life Sciences towards particular developments related to the use of technology in learning, teaching and assessment, as well as identify existing skill sets in order to appropriately plan for any implementation. The context for this study is largely driven through institutional strategy, which in itself is informed directly from the student voice. In particular, this research focused on: Introduction of minimum standards for all module areas within the virtual learning environment (VLE); Introduction of online submission of coursework (as well as electronic marking and 
feedback); and the recording of lectures. Each area of focus aligns to at least one of the recommendations from HEFCE for the use of technology to improve efficiency or to enhance or transform teaching and learning.

\section{Introduction of minimum standards}

Amidst the plethora of innovation taking place across the higher education sector, introducing minimum standards for VLE areas might appear 'low-tech', but the inconsistent experience between module presence in the VLE is a 'significant factor for their [students] dissatisfaction' (Bee 2013), and such reports of disparity from the 'student voice' are not uncommon across higher education (Ahmed and Morley 2010). Students come to expect consistent information across their VLE areas, and to be able to access course/module material in a consistent manner. Information such as contact details for module leaders, assessment requirements and reading lists appear to be obvious elements that should be made available to learners within any module. Reed and Watmough (In press) relate the introduction of minimum standards to student satisfaction through hygiene factors, and suggest implementing many of these factors can reduce dissatisfaction.

Ellis and Calvo (2007) suggest the introduction of minimum standards relies heavily on strong leadership and policy, and without such, 'one cannot realistically expect enduring and influential growth and change' (p. 63).

\section{Online submission}

Despite increasing NSS satisfaction across the board, 'Assessment and Feedback' consistently reports lower levels of satisfaction than other aspects of the higher education experience $(2011=68 \%$ satisfaction; $2012=70 \%$ satisfaction) (HEFCE 2012). Focusing on issues to enhance the student experience of assessment and feedback is therefore an obvious aim, with recurring themes being raised such as cost of printing, timeliness and legibility of feedback and flexibility of assignment submission.

Whilst it is recognised the re-engineering of assessment-feedback processes is a challenging task, existing systems can be used to support such changes (standard VLE tools and third-party plugins such as Turnitin/Grademark). A number of authors cite feedback from academic staff in the use of such systems. For example, Buckley and Cowap (2013) emphasise the suitability of Turnitin/Grademark for plagiarism detection and electronic marking but also highlight the surrounding technical difficulties. Other authors cite positive feedback in relation to reduced amounts of plagiarism, higher quality of work produced and reduced time/workload as a result of useful QuickMark features (Johnson, Nádas, and Bell 2010; Rolfe 2012). Furthermore, an area of increasing interest in this regard is the introduction of assessment analytics (Ellis 2013), which might enable academics greater insight into staff and student performance on written assignments.

\section{Recording of lectures}

A number of researchers suggest positive impacts related to the implementation of lecture capture systems (Barokas et al. 2010; Deal 2007; Folley 2010; Toppin 2010), as it enables:

- Students to review content at their own pace.

- Search/View associated visual aids for concepts concurrently. 
- Efficient and economical ways to convey complex information to large student groups.

- A means to provoke thought and deepen understanding.

- Development of independent learning.

- Support to overcome weaknesses in areas such as taking notes, paying attention over extended periods of time, or dealing with pronunciation challenges presented by some lecturers whose first language is not English.

A recurring concern expressed by academics throughout the literature is the potential for lecture capture to negatively impact on class attendance, but published research suggests the opposite-provision of recordings does not negatively impact on class attendance (Barokas et al. 2010; Deal 2007; Toppin 2010). Toppin (2010) identifies learner preferences for pre-recorded lectures $(40 \%$ of respondents) over live recordings $(29 \%)$, with others having no preference $(31 \%)$. Furthermore, recorded footage was less likely to be viewed if students were in class.

Issues of 'ownership' (or IPR) are raised by Barokas et al. (2010) as PowerPoint presentations often include images where copyright is unclear, for example, images/ diagrams taken from publications or Google Images.

The three areas discussed form the focus of this research and provide useful data to inform the implementation of any strategic decisions, some of which are naturally easier to achieve than others.

\section{Methodology}

This paper presents a 'snapshot' case study (Jensen and Rodgers 2001) which establishes a detailed, objective study of one research entity at a single point in time, with the aim of identifying the experience and attitudes of teaching staff towards a range of TEL activities and initiatives detailed earlier. The project takes an exploratory focus to gain insight into staff attitudes and experience in distinct aspects of TEL that are of current interest to the wider higher education community, and of particular interest to the TEL strategy in the institution under study. It takes the view that staff attitudes and experience in these specific aspects are critical for the successful implementation of the strategy. Whilst these areas are of relevance across the sector more generally, this research provides a view of just one Russell Group University in the United Kingdom. As such, any results are representative of the point in time at which the research was conducted, and may be subjected to change as a result of further initiatives. As a result of this, along with very nature of the fast changing TEL landscape and the unique nature of teaching departments and research institutes, it will be difficult to generalise results from this research to other faculties and institutions. However, it might provide a reference point for future research across the sector in relation to the specific areas under investigation.

\section{Questionnaires}

An online questionnaire was developed and distributed via e-mail to all staff within the Faculty of Health and Life Sciences, to be completed by anyone with teaching responsibilities. This covers the Institute of Learning and Teaching, the six academic schools (Medicine; Health Science; Veterinary Science; Life Science; Dentistry; and Psychology) and the five research institutes (Ageing and Chronic Disease; Infection 
and Global Health; Integrative Biology; Psychology, Health and Society; and Translational Medicine).

Given the complex structure of the Faculty, an initial email was sent on 26 July 2013 to school administrators and research institute managers for dissemination in their respective areas. A follow up email was sent to these same people on 14 August 2013, requesting a repeat dissemination in an attempt to boost survey responses. Due to this distribution method, an accurate response rate is difficult to ascertain.

The survey was split into three sections: general TEL/VLE; online submission, marking and feedback; and lecture capture/recordings (key themes taken from the previous SU report and those forming strategic agenda). It contained a mixture of open and closed questions, as well as questions with standard Likert scales. It was anticipated that the variety of question types would enable a broad range of feedback to be obtained, and all questions were optional resulting in a range of completed questions throughout the questionnaire.

Although ethics approval was not sought for this research, the British Educational Research Association's revised guidelines were considered, and particularly the concept of 'Voluntary Informed Consent' (BERA 2011). The questionnaire was also distributed for comment and approval to the Faculty TEL Steering Group.

The questionnaire has been included in Appendix.

\section{Results}

The response rate (n) across questions varies, as they were all optional. The questionnaire software used shows that the questionnaire was viewed 156 times, but the highest response rate to any question was 100 .

Respondents had the opportunity to leave additional comments at the end of each section, as well as general comments at the end of the questionnaire. A total of 67 comments were received and are summarised alongside the data from the corresponding section.

\section{Section 1: Minimum standards and TEL}

Minimum standards

$91 \%$ of respondents $(n=89)$ believed minimum standards should be introduced for VLE areas (Q1). Of the 9\% of respondents who answered 'No', none went on to explain their reason in the follow-on conditional question.

Respondents $(n=100)$ then went on to identify specific information/tools (Q2) from a list that should be included in any such minimum standards (Figure 1). A 'basic presence' (75\%), lecture notes/handouts (72\%) and contact details for the module leader/convener $(71 \%)$ were the options that received the most responses. Online discussion forums (27\%), opportunity for online formative assessment $(37 \%)$ and ability to submit coursework online $(38 \%)$ were the least popular options to be included in any minimum standards.

\section{Attitudes and experience to various aspects of TEL}

Respondents $(n=90)$ were asked to identify their attitude/experience against a range of activities/statements, with options to declare if they: Disagreed with statement; 


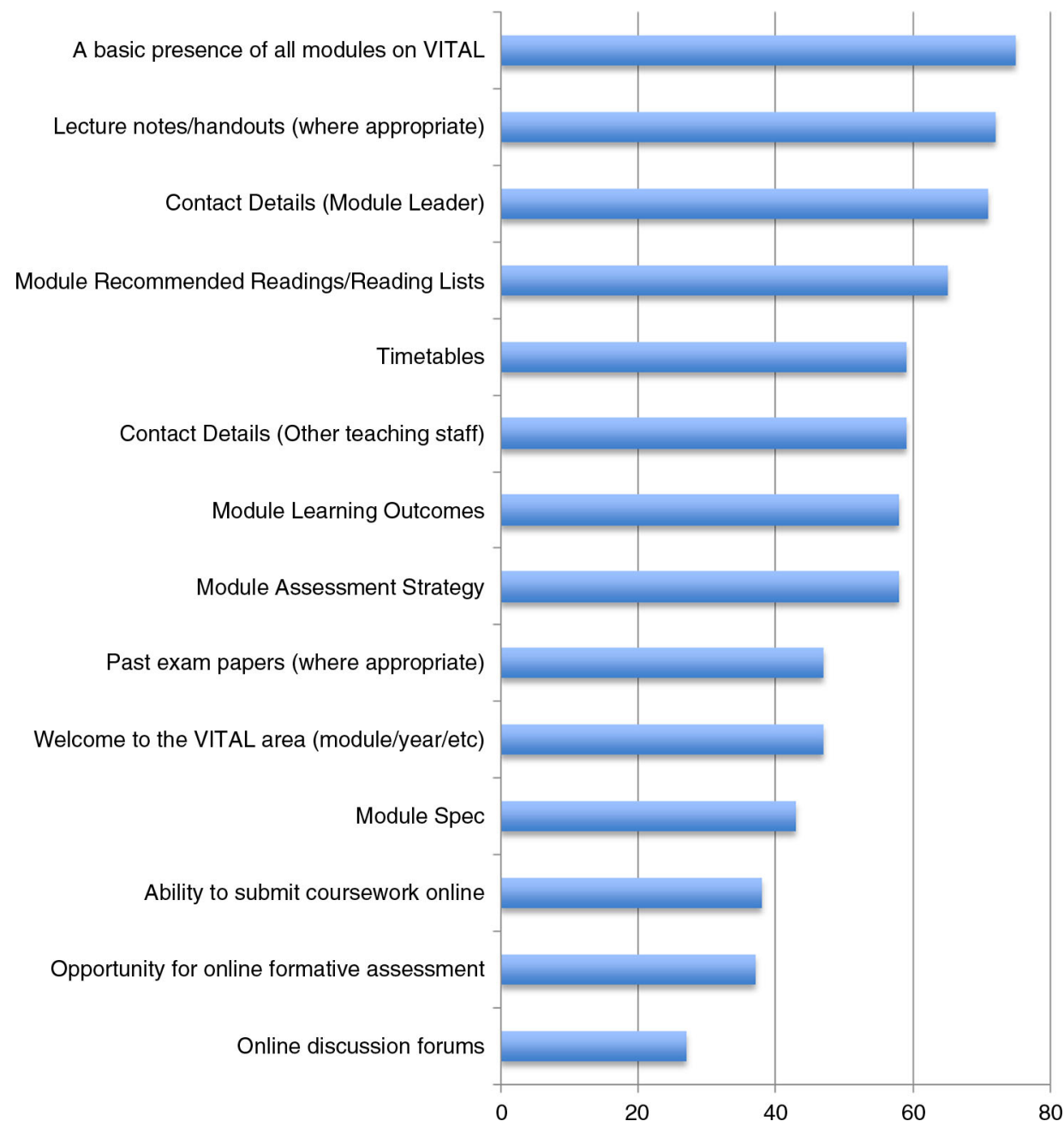

Figure 1. Identification of information/tools for VLE minimum standards.

Never heard of statement; Would like to learn more; and/or Have experience with statement.

Few respondents disagreed with the statements provided; however, 'Social Networking in Learning and Teaching' was the option that polarised opinion most $(35 \%$ disagreed, $9 \%$ never heard of it, $30 \%$ would like to learn more and $26 \%$ have experience).

Provision of lecture materials was the option that respondents had most experience with $(97 \%)$.

Copyright and IPR (61\%), developing interactive online content $(60 \%)$, use of mobile devices and apps (57.5\%), developing video (55\%) and online marking/feedback tools $(53 \%)$ were the areas that respondents were most keen to learn more about.

\section{Barriers and challenges to innovating with technology}

Respondents $(n=100)$ went on to identify barriers from a list that currently inhibit them from innovating with technology in their teaching $(n=89)$. They were also asked to identify any interventions (free-text) that may help overcome such 
barriers $(n=51)$. Sixty one points were loosely coded to 19 unique interventions (Tables 1 and 2).

\section{General comments for Section 1}

A number of free-text responses were made by respondents at the end of Section 1, identifying a range of different issues. These include:

- There was recognition of the need to encourage greater consistency between VLE areas (module and/or year areas) to prevent a disjointed student experience.

- Achieving such consistency through the implementation of VLE minimum standards will require significant support.

- Questions were also raised around policing of minimum standards to ensure consistency is actually achieved.

- The use of learning technologies should be valued more and built into PDR/ Promotion.

- The VLE received mixed views from some respondents, with some feedback raising concerns/problems with the software.

- Mix in attitudes towards who should actually do this work - some suggesting it should be done by dedicated IT support staff.

- Any automation of VLE minimum standards would be advantageous to prevent additional staff workload.

\section{Section 2: Online submission, marking and feedback}

This section included questions to ascertain staff experience and attitudes to supporting online submission, marking and feedback.

\section{Encouraging online submission}

Respondents were asked if they had encouraged students to submit coursework online. Figure 2 demonstrates the extent to which respondents $(n=88)$ have encouraged online submission.

The chart demonstrates that very few respondents (1\%) 'do not want to do' online submission, and $66 \%$ have encouraged online submission in some form (either completely online submission or online submission alongside a paper copy).

Eleven percent of respondents chose 'other', leaving comments including 'not applicable' and 'Haven't had the opportunity yet'. There was also a comment on personal experience: 'As an Oxford ContEd mature student I have found online submission excellent'.

Table 1. Barriers to using TEL.

Barriers

Responses (\%)

Lack of time to innovate in teaching

Lack of support/training opportunities

No reward structures for innovation in teaching

Priorities lie elsewhere, for example, research

Lack of skills/literacy to innovate

Lack of motivation to innovate 
Table 2. Interventions to overcome barriers.

Interventions

Training/workshops/guides

Support/mentoring/more IT staff

More time/less workload

Needs to be easy to use

More IT/TEL support in ILT

Recognition/reward for good work

Dedicated staff to do the technical work

More staff

Investment in kit (projectors, clickers)

Research is priority

Link innovation to promotion/PDR

Evidence base for TEL use

Embed technology rather than as an add-on

Address teaching versus research versus admin balance

Networked software

Leadership/strategy at ILT level
Responses (n)

16

14

8

5

4

4

4

2

2

2

2

1

1

1

1

1

Question $8(n=63)$ went on to ask if respondent's prior experience of online submission had been positive or negative (Figure 3). Eighty four percent reported positive experiences and $16 \%$ reported negative experiences.

\section{Online marking and feedback}

Questions 9-11 related to experiences of online marking and feedback. Question $9(n=87)$ identified that $74 \%$ of respondents had provided electronic feedback previously.

A follow-on question $(n=69)$ asked respondents to identify their view against a list of statements (as earlier) related to the provision of electronic feedback, including the use of Microsoft Word, Turnitin/Grademark, audio feedback and video feedback.

Respondents were given the opportunity to detail any other systems used for the provision of electronic feedback (Question 11). Thirty free-text comments were left, with 'email' the most common answer $(n=8)$. Some responses also suggest misunderstanding with the terms provided, as some free-text comments included 'rubrics in

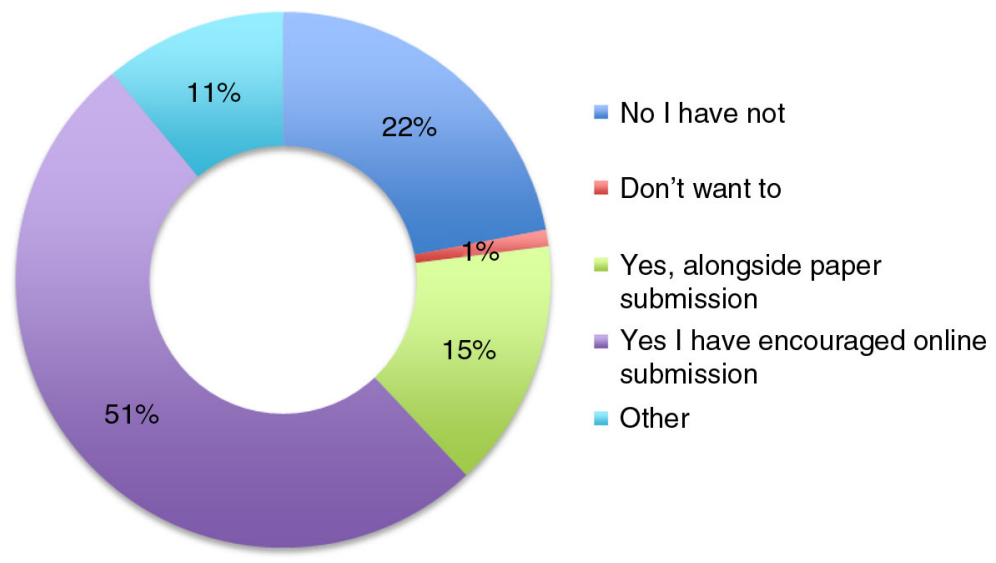

Figure 2. Encouraging online submission. 


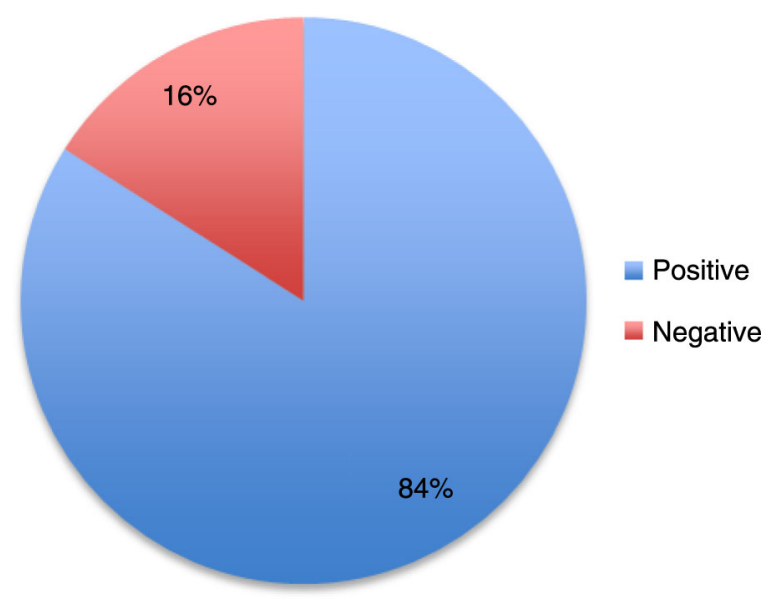

Figure 3. Experience of online submission.

Turnitin', 'Track changes for formative feedback', 'Highlighted word document with typed advice'. As these options may have been covered by the options provided, it suggests they could potentially be presented more clearly.

An additional question (Question 12) asked respondents: If you were to use any system for enabling learners to submit work online AND/OR mark work electronically, what system features and workflows would you expect? Thirty nine free-text responses were received, with comments around 'ease of use' by far the most common. Other comments expressed a desire to mark across devices (including tablets), support for anonymous and group marking/feedback, flexibility to leave in-text audio comments and a robust system to cope with large cohorts.

There was also a mix of positive and negative comments towards existing systems (Blackboard, Turnitin/Grademark).

\section{General comments from Section 2}

A number of free-text responses were made by respondents at the end of Section 2, identifying a range of different issues. These include:

- Challenges exist with respect to marking group work online, which can provide a significant barrier in future.

- Some concerns were raised regarding the suitability of the VLE (Blackboard) as well as Turnitin and Grademark for the marking of student work.

- Electronic submission can help provide 'better' feedback 'quicker', but it may not fit with everyone's workflows.

\section{Section 3: Recording materials for learners}

This section asked respondents about recording materials for learners and aimed to identify experience, attitudes and drivers to recording materials.

Question 14 asked respondents to identify their views against a list of statements (as earlier) related to the provision of recorded materials for learners $(n=84)$. Figure 4 demonstrates respondent's attitudes and experience to recording materials, including the provision of screencasts, 'flipping the classroom' and full lecture capture. 


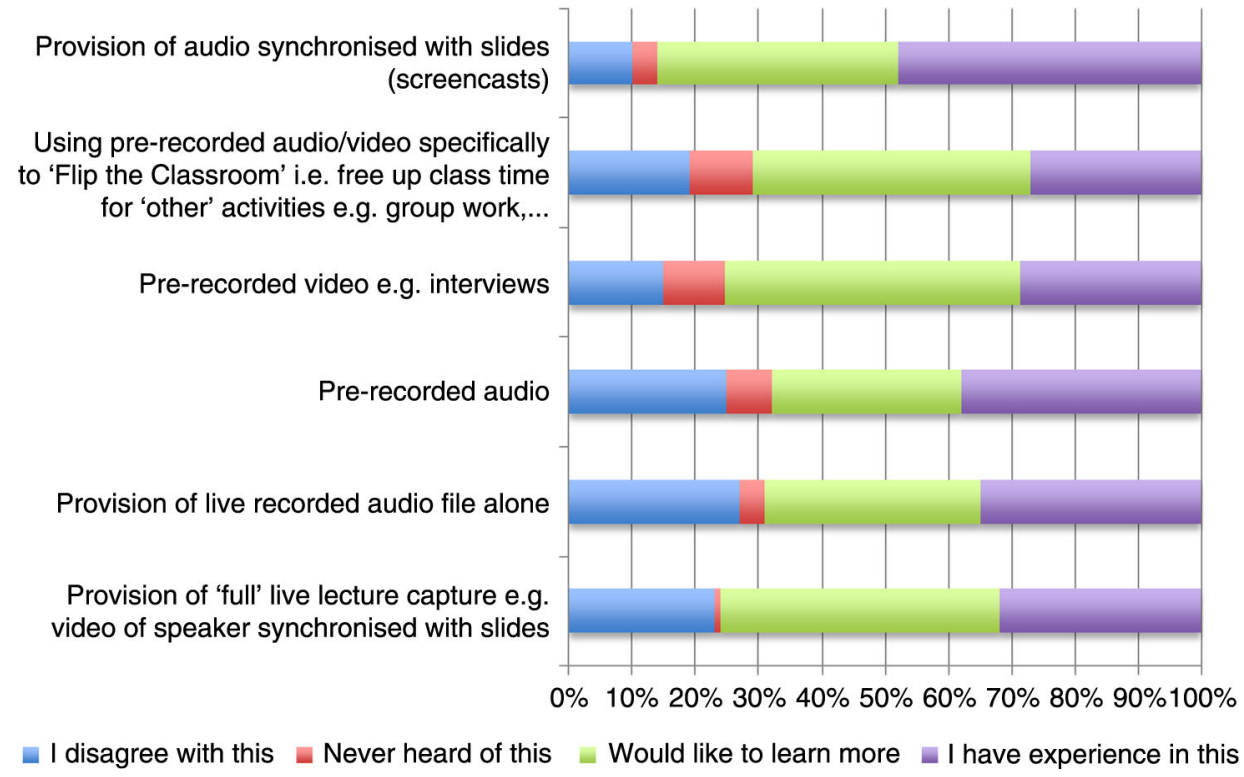

Figure 4. Attitudes \& experience to recording materials.

\section{Barriers and drivers for recording materials for learners}

Respondents were asked to identify potential drivers to encourage the provision of recorded materials $(n=94)$, as well as barriers preventing engagement in this area $(n=94)$ (Table 3).

Comments left from respondents selecting 'Other' included:

- Recorded materials can save time and release me for other roles $(\times 3)$

- Can increase consistency for distance students

- Can increase the challenge and reduce spoon feeding

- Support is required from the computing services department, and software/ hardware is required in all lecture halls

- Funding will be required to create the materials and manage technology infrastructure

- Provide lecture preview or give lecture when I cannot be there (Table 4)

Table 3. Drivers to engage with recording materials.

Drivers

Responses (\%)

To increase flexibility of learning, for example, pace and place of content review $\quad 54$

Support for students with specific learning difficulties, for example, dyslexia $\quad 50$

$\begin{array}{ll}\text { Develop independent learning } & 47\end{array}$

$\begin{array}{ll}\text { To create a blend of face-to-face and online sessions } & 45\end{array}$

$\begin{array}{ll}\text { To support assessment preparation } & 38\end{array}$

Efficient/effective way to communicate complex information 38

$\begin{array}{ll}\text { Overcome language barriers } & 29\end{array}$

$\begin{array}{ll}\text { Overcome challenges related to note-taking } & 29\end{array}$

Overcome challenges related to sustaining concentration 28

$\begin{array}{ll}\text { To overcome challenges of available space } & 14\end{array}$

Other (please specify) 
Table 4. Barriers preventing engagement with recording materials.

\begin{tabular}{lc}
\hline Barriers & Responses (\%) \\
\hline Lack of time & 49 \\
Students won't attend class & 33 \\
Students won't pay attention during class & 26 \\
Disagree with the concept & 10 \\
Other (please specify) & 14 \\
\hline
\end{tabular}

Comments left from respondents selecting 'Other' included:

- Lack of feedback to lecturer/teacher is a negative aspect of recording lectures $(\times 3)$

- Lack of technological ability and support will prove challenging $(\times 4)$

- Training in the systems/software is essential for mass lecture capture to succeed

- Students who MOST need to attend class may stop doing so as lectures are recorded

- Students will only use recorded material for assessments and not do personal reading

- Academic staff fear of wider distribution of lectures beyond enrolled students

- Academic staff fear of making mistakes in lectures that are recorded and distributed

- No guarantee that solutions will work across platforms

- Provision of recorded materials 'actively inhibits' acquisition of note-taking skills.

An additional question (Question 17) asked respondents: 'If you were to use any system for recording materials (pre-recorded or live) what system features and workflows would you expect?' Thirty six free-text responses were received, with comments around 'ease of use' by far the most common. A number of comments also related to both Camtasia and Mac software for recordings, as well as a need for support in this area.

General comments from Section 3

A number of free-text responses were made by respondents at the end of Section 3, identifying a range of different issues. These include:

- Some experience in recording using various methods already exists amongst academic staff.

- Some disagreement with recording lectures based on view that it will impact class attendance.

- View that learning to take notes, concentration and deep thinking are skills learned through attending lectures and providing recordings contradicts this.

- Automation and/or simple workflows are important for lecture capture technologies to be successful.

- Some preference to record specific content rather than record whole lectures.

Other general comments from questionnaire

At the end of the questionnaire, respondents had the opportunity to leave additional general comments. Points of note included:

- Positive feedback to the use of technology to support and enhance learning and teaching. 
- Time to innovate with technology a significant barrier.

- Emphasis on pedagogy, and technology is an aid to teaching.

- Some concerns about IT infrastructure, for example, Wi-Fi and suitable projectors in lecture rooms across campus.

- Need for suitable support.

- Some views that IT/learning technologist staff should do all of this work for lecturers.

\section{Discussion}

\section{Section 1: General TEL and minimum standards}

Data from Section 1 identifies that respondents generally agree (91\%) with the introduction of minimum standards, with a basic VLE presence for all modules $(75 \%)$ including lecture notes/handouts $(72 \%)$, contact details for module conveners $(71 \%)$ and reading lists $(65 \%)$. Contact details for other teaching staff $(59 \%)$, timetables $(59 \%)$, module learning outcomes (58\%) and assessment strategy $(58 \%)$ were also popular inclusions.

Free-text comments suggest these elements should be automated wherever possible, and for other developments beyond automation, it is felt more support is required, be it in the shape of training; accessible support materials; or for some respondents, dedicated staff available to carry out this work on their behalf. This latter point might reinforce a lack of ownership for teaching though. Finally, it is also important that pedagogic value is the leading driver for the introduction of any such technologies in order for staff to fully buy-in to developments.

Figure 5 demonstrates staff attitudes/experiences towards a range of activities. A huge proportion of respondents had experience with activities such as providing lecture materials $(93 \%)$, and whilst other aspects had less direct experience, there was a general willingness to learn more. For example, respondents would like to learn more about copyright and IPR (61\%), interactive online content $(60 \%)$, mobile devices and apps (57\%), video (55\%) and online marking/feedback (53\%). It is natural that these topics might feed into planning discussions, be it in the shape of investment in hardware/software, training/support, dedicated technical staff, etc.

There was very little negativity towards the activities provided, other than the use of social networking. This was the single option that received the greatest number of 'I disagree with this' responses (35\%). Although the use of such tools is often seen as controversial, research does suggest overwhelmingly positive uses (Junco, Heiberger, and Loken 2011; Reed 2013; Roblyer et al. 2010). Although this might not be a faculty-wide approach, support should be available for those interested in investigating this area further.

Respondents identified a range of barriers to innovating with technology, consistent with those raised in the literature - the most common in this study being the lack of time available to engage to a greater level (61\%). This could be closely aligned with 'competing priorities' $(30 \%)$ as there is a high expectation upon other activities such as research. The lack of reward mechanisms in place for innovation in teaching was also an issue for some $(31 \%)$.

Interestingly, respondents identified a lack of support/training (32\%) and a lack of skills $(29 \%)$ as barriers, which closely aligns with the potential interventions that were identified, for example, training/workshops/guides $(n=16)$ and support/mentoring/ 
Provision of lecture materials (presentations, handouts, etc)

Online submission tools

Use of VITAL to provide support information

Linking to external sites

Online marking/feedback tools

Developing interactive online content

Reusing existing materials (that are suitably licensed) e.g. other people's animations,...

Consciously dealing with Copyright and Intellectual Property Rights related to...

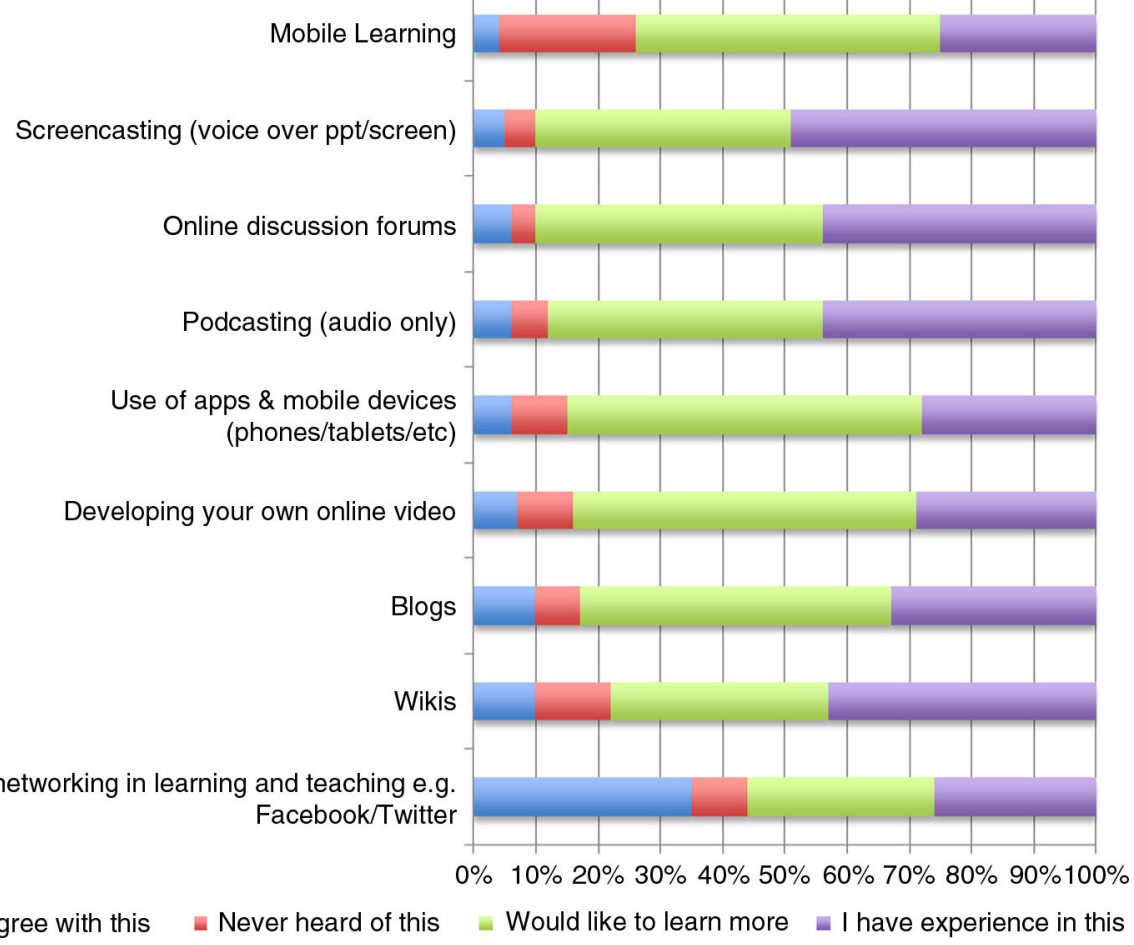

I disagree with this $\quad$ Never heard of this Would like to learn more $\quad$ I have experience in this

Figure 5. Attitudes \& experience to various aspects of TEL.

more IT staff $(n=14)$. This suggests targeted training and support might increase staff engagement with various aspects of TEL.

The general positive response to the use of TEL is important given the potential links between the use of the VLE (and other learning technologies) and student satisfaction. However, in line with the suggestions of Ellis and Calvo (2007), positive 
attitudes from academic staff may not be enough, with a clear suggestion for strong leadership and policy in this area. Furthermore, whilst many of the activities discussed thus far are less technical and within the scope of academic activity (uploading information to the VLE, e-marking, etc.), it is recognised that some activities are more difficult and may require specific technical expertise (e.g. recording/editing of video). Therefore, the role of both support staff and staff development programmes are critical for continued growth in this area, and something that should not be overlooked or underestimated. This might cater to simultaneous top-down and bottom-up activity in relation to TEL.

In relation to the aspects of practice that HEFCE identify, the introduction of minimum standards could align closely with both efficiency and enhancement (HEFCE 2009), as access to the specific information such as those detailed can save time and cost related to printing, storage and access from staff and students. For example, immediate access to timetables or contact information via mobile devices could support the daily needs and requirements of students.

\section{Section 2: Online submission, marking and feedback}

Data in Section 2 identified that only $1 \%$ of respondents did not want to engage with online submission, marking and feedback, with $84 \%$ of respondents reporting positively on the use of such approaches. Figure 2 identified a range of existing practices, such as the online submission alongside the submission of a paper copy $(15 \%)-$ a practice which perhaps duplicates time and effort. Linking back to the emphasis placed on staff development earlier, this could be one focus to raise awareness to the possibilities and affordances of moving to completely online submission, marking and feedback.

Figure 6 demonstrates respondents were largely experienced in using Microsoft Word (track changes) to provide feedback (92\%), with Turnitin/Grademark and audio feedback areas where respondents wanted to learn more (48 and $37 \%$, respectively). Free-text comments also raised the potential for marking on tablet devices. The positivity towards online submission, marking and feedback might feed into discussions and pilot projects focusing on solutions to effectively manage essential processes in the assessment-feedback cycle, for example, potential suitability of the Turnitin iPad app for tablet (and offline) marking. Again, awareness raising and staff development could play a significant role here.

The data from both Section 1 (general VLE/TEL and minimum standards) and Section 2 (Online submission, marking and feedback) is generally positive in relation to staff attitudes towards the various issues/activities. However, it is apparent that significant work to train and support staff is required to engage with such approaches at a department/faculty level, and comments suggest that easy-to-use systems are critical. Any potential to save time here would be beneficial, for example, automation.

Redeveloping business processes around the management of assessment clearly aligns to HEFCE's suggestion of both enhancement and transformation. Adopting online tools to support processes of assessment and feedback are obvious considerations, but completely transforming business processes around the management and administration of assignments could reap greater rewards in areas typically not considered in the literature, such as programme administration teams, and so on. Furthermore, consideration of assessment analytics as suggested by Ellis (2013) could provide greater insight into teaching and the marking of student work. 
I have used Microsoft Word ('track changes' feature) to provide feedback

I have used Turnitin/Grademark to provide feedback

I have used video to provide feedback e.g. recorded screencasts (screen recording) to provide feedback

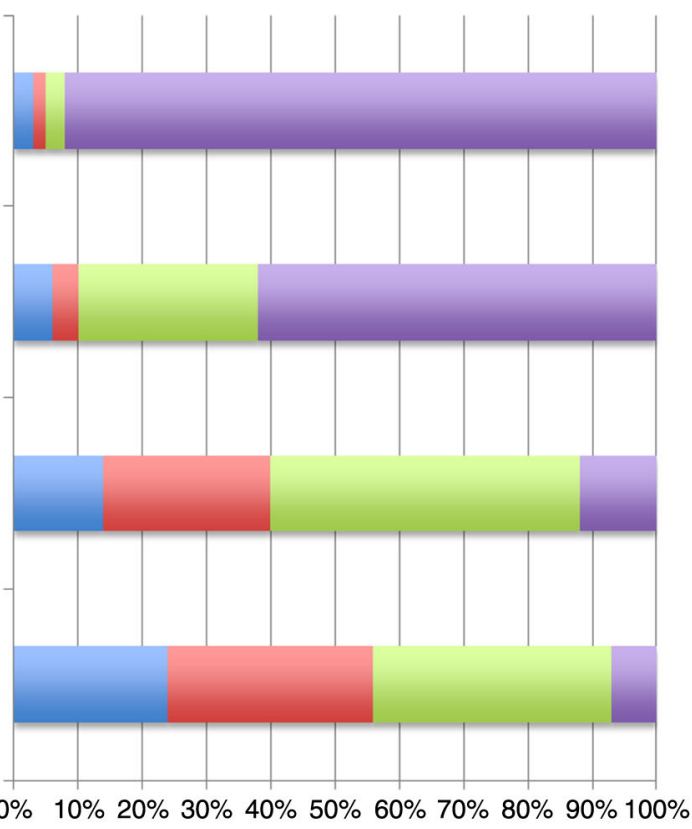

I disagree with this $\quad$ Never heard of this

Would like to learn more

I I have experience in this

Figure 6. Attitudes \& experience to electronic feedback.

\section{Section 3: Staff attitudes and experience towards recording materials/lectures}

Figure 4 demonstrates greater resistance to recording materials, either live or prior to teaching, than has been identified in the other sections in this research. However, there were still at least $70 \%$ of respondents who either have experience of or want to learn more about each method listed. The provision of audio synchronised with slides (screencasts) was the most popular option (86\%). The biggest drivers to engaging with recording content were related to increasing flexibility for learning (54\%) and supporting learners with specific learning difficulties (SpLDs) (50\%). Comments also related to freeing up staff time as a result of providing recordings. However, despite the evidence presented in literature there was significant concern (in standard questions and free-text comments) that providing lecture recordings would impact on class attendance. Based on this assertion there was also concern that recordings would impact on feedback mechanisms within face-to-face classes (due to attendance issues), as well as a negative impact on student attention and skills such as notetaking. One free-text response did identify (through experience) the 'misguided concern' on the impact of attendance. Lack of time was again the most significant barrier to engaging with this approach (49\%).

It is important therefore that any strategic progress in relation to the provision of recordings is preceded with suitable communication and presentation of literature/ research, as well as effective ways to present recordings to learners. Possibly more important here than in relation to other technologies/tools discussed, is a simple workflow to enable recording and publishing of content. Manually recording video/ audio, editing and publishing is a technical, expensive and time-consuming activity; therefore, automated systems with simple workflows are essential if this is to be scalable at a faculty/institutional level. 
In respect of HEFCE's three levels of impacting on learning and teaching, the recording of lectures aligns clearly to both efficiency and enhancement. If students can return to the lecture to revisit aspects they did not understand (as identified in the literature), it is logical to expect fewer queries about content. This availability also provides greater efficiency for student when preparing for assessment.

\section{Conclusion}

This research was driven by institutional strategy and set out to investigate staff attitudes and experiences towards using TEL in a range of ways. The data obtained has been presented to Faculty management and will be of interest to those across the wider sector interested in or benchmarking against staff attitudes and experience to TEL.

Evidently there is great interest across the Faculty of Health and Life Sciences in various aspects of TEL, ranging from everyday use of the VLE; through to online submission, marking, and feedback; and the provision of recorded materials for learners.

The topics covered in the staff questionnaire relate to HEFCE's levels of efficiency, enhancement and transformation (HEFCE 2009). Based on the quantitative and qualitative data collected in this study, staff align mostly with the level of efficiency (cost, time, scalability, sustainability). In particular, staff were concerned with the impact of TEL initiatives on their time - specific mention of automation of minimum standards and the recording of lectures to save, or free up time for other activities. 'Lack of time' was also cited as a barrier to engagement (evident in each section of the questionnaire), as well as some suggestions of the need for more technical staff to carry out TEL activities on behalf of academics.

Although Efficiency was a key aspect for the introduction of technology, respondents still aligned with activities related to enhancing and transforming practices, particularly through online submission and the recording of lectures.

Despite the interest in various TEL initiatives, there are still a number of challenges that the staff face, including competing demands for time (as mentioned above), a lack of skills/literacy and a need for more support and training, all of which resonate with the barriers presented in the literature. Furthermore, clear explanation emphasising the pedagogic value of initiatives is important to teaching staff, as are systems that are intuitive and easy to use.

A key message throughout the data is the need for more support, and as reinforced through the Kregor et al. (2012) quote earlier, the success of any strategy will ultimately rest on those implementing it. Therefore, support should take many forms, for example, accessible guidance materials, regular training/workshops and technical support for more difficult activities.

This case study provides a snapshot of attitudes and experience in relation to TEL, and is unique in many ways, for example, nature of HEI (research intensive/ Russell Group), specific subject areas (Health and Life Sciences) and, obviously, taken from a particular point in time. It is very likely that the data obtained would be dramatically different if the study were to be repeated post-implementations and may be different to other higher education institutions.

As a result of the data obtained in this study, a number of high-level recommendations for managers and TEL support teams appear apparent, including:

- Clarifying position on the importance of learning and teaching, and the responsibilities/expectations of academic staff in respect to this. 
- Communicate investment into TEL, including support structures in place within the faculty at academic/strategic and technical support levels, along with central university support.

- Identify appropriate staff development opportunities to enable staff to engage with the various tools/technologies/approaches to enhance learning, teaching and assessment. Strategic/policy decisions will likely have significant demands from a staff development perspective (considering frequency and number of sessions), raising a need to clarify roles/responsibilities between departments, for example, training provided within the Faculty or led by central e-learning support and computing services departments.

On the whole, the data provide a somewhat mixed response to Kregor et al.'s (2012) suggestion of a 'disconnect' between the staff and the student perspectives. While there remains caution to some innovative uses of technology, most academic staff are positive about the role of technology to enhance learning and recognise their need to engage with it more.

\section{References}

Ahmed, J. \& Morley, G. (2010) 'VLE a blessing or a curse: VLE use by HE academic staff', Global Learn Asia Pacific 2010 - Global Conference on Learning and Technology. Available at: http://eprints.hud.ac.uk/8901/

Attwell, G. \& Pumilia, P. M. (2007) 'The new pedagogy of open content; bringing together production, knowledge, development and learning, Science, vol. 6, pp. 211-219.

Barokas, J., et al., (2010) 'Lecture capture: student perceptions, expectations, and behaviors', eds J. Sanchez \& K. Zhang, Digital Media, pp. 1-8. Available at: http://www.informatik. uni-osnabrueck.de/papers_pdf/2010_02.pdf

Bee, T. (2013) Making the Most Out of IT: Report to TELWG, Liverpool Guild of Students, Liverpool.

BERA. (2011) Ethical Guidelines for Educational Research, BERA, London.

Buckley, E. \& Cowap, L. (2013) 'An evaluation of the use of Turnitin for electronic submission and marking and as a formative feedback tool from an educator's perspective', British Journal of Educational Technology, vol. 44, no. 4, pp. 562-570. Available at: http://doi.wiley. com/10.1111/bjet.12054

Charlesworth, A., et al., (2007) 'Sharing eLearning content - a synthesis and commentary final report', Synthesis, vol. 31. Available at: http://ie-repository.jisc.ac.uk/46/

Deal, A. (2007) Lecture Webcasting: A Teaching with Technology White Paper, Carnegie Mellon, Pittsburgh.

Ellis, C. (2013) 'Broadening the scope and increasing the usefulness of learning analytics: the case for assessment analytics', British Journal of Educational Technology, vol. 44, no. 4, pp. 662-664. Available at: http://doi.wiley.com/10.1111/bjet.12028

Ellis, R. \& Calvo, R. (2007) 'Minimum Indicators to Assure Quality of LMS-supported Blended Learning', Educational Teechnology \& Society, vol. 10, no. 2, pp. 6-70.

Folley, D. (2010) 'The lecture is dead long live the e-lecture', Electronic Journal of e-Learning, vol. 8 , no. 2, pp. 93-100.

HEFCE. (2009) 'Enhancing learning and teaching through the use of technology: A revised approach to HEFCE's strategy for e-learning', Higher Education Funding Council for England, March 2009, Available at: http://www.hefce.ac.uk/pubs/year/2009/200912/\#d.en. 63806

HEFCE. (2012) 'Press release: highest ever satisfaction rates in 2012 student survey'. Available at: http://www.hefce.ac.uk/news/newsarchive/2012/name,75522,en.html

Jensen, J. L. \& Rodgers, R. (2001) 'Cumulating the intellectual gold of case study research', Public Administration Review, vol. 61, no. 2, pp. 235-246.

Johnson, M., Nádas, R. \& Bell, J. F. (2010), 'Marking essays on screen: an investigation into the reliability of marking extended subjective texts', British Journal of Educational Technology, vol. 41, no. 5, pp. 814-826. Available at: http://doi.wiley.com/10.1111/j.1467-8535.2009.00979.x 
Junco, R., Heiberger, G. \& Loken, E. (2011) 'The effect of Twitter on college student engagement and grades', Journal of Computer Assisted Learning, vol. 27, no. 2, pp. 119-132. Available at: http://doi.wiley.com/10.1111/j.1365-2729.2010.00387.x

Kirkwood, A. \& Price, L. (2013) 'Technology-enhanced learning and teaching in higher education: what is "enhanced" and how do we know? A critical literature review', Learning, Media and Technology, pp. 1-31. Available at: http://www.tandfonline.com/doi/abs/10.1080/ 17439884.2013.770404

Kregor, G., Breslin, M. \& Fountain, W. (2012) 'Experience and beliefs of technology users at an Australian university: keys to maximising e-learning potential', Australasian Journal of Educational Technology, vol. 28, no. 8, pp. 1382-1404.

Newton, R. (2003) 'Staff attitudes to the development and delivery of e-learning', New Library World, vol. 104, no. 10, pp. 412-425.

Reed, P. (2012) 'Awareness, attitudes and participation of teaching staff towards the open content movement in one university', Research in Learning Technology, vol. 20, no. 1063519, pp. 1-14.

Reed, P. (2013) 'Hashtags and retweets: using Twitter to aid community, communcation, and casual (informal) learning', Research in Learning Technology, vol. 21, 19692. Available at: http://dx.doi.org/10.3402/rlt.v21i0.19692

Reed, P. \& Watmough, S. (in press) 'Hygiene factors: using VLE minimum standards to avoid student dissatisfaction', eLearning and Digital Media, vol. 12, no. 1, 2015.

Roblyer, M. D., et al., (2010) 'Findings on Facebook in higher education: a comparison of college faculty and student uses and perceptions of social networking sites', The Internet and Higher Education, vol. 13, no. 3, pp. 134-140.

Rolfe, V. (2012) 'Open educational resources: staff attitudes and awareness', Research in Learning Technology, vol. 20, no. 1063519, pp. 1-13.

Salmon, G. (2005) 'Flying not flapping: a strategic framework for e-learning and pedagogical innovation in higher education institutions', Alt-J, vol. 13, no. 3, pp. 201-218.

Salmon, G., Jones, S. \& Armellini, A. (2008) 'Building institutional capability in e-learning design', Alt-J, vol. 16, no. 2, pp. 95-109. Available at: http://www.tandfonline.com/doi/abs/ $10.1080 / 09687760802315978$

Seonghee, K. \& Boryung, J. (2008) 'An analysis of faculty perceptions: attitudes toward knowledge sharing and collaboration in an academic institution', Library \& Information Science Research, vol. 30, no. 4, pp. 282-290.

Toppin, I. N. (2010) 'Video lecture capture (VLC) system: a comparison of student versus faculty perceptions', Education and Information Technologies, vol. 16, no. 4, pp. 383-393. 


\section{Appendix - Questionnaire sent to staff}

Section 1: Use of the VLE

The use of the VLE by teaching staff has become a key expectation amongst students. This first section aims to gather your experiences and attitudes towards the VLE and a few other tools/ technologies.

1. Introducing 'minimum standards' for VLE areas can help address issues of consistency, enabling learners to easily access important information such as contact details of teaching staff, assessment requirements, lecture materials, etc.

Do you think there should be any minimum standards for VLE use?

[Yes/No]

2. If you answered 'Yes' to Q1, what information do you believe all students should have access to within each VLE area? (Please select all that apply)

A basic presence of all modules on the VLE

Welcome to the VLE area (module/year/etc.)

Module recommended readings/reading lists

Module assessment strategy

Opportunity for online formative assessment

Contact details (module leader)

Contact details (other teaching staff)

Timetables

Module learning outcomes

Online discussion forums

Module Spec

Past exam papers (where appropriate)

Ability to submit coursework online

Lecture notes/handouts (where appropriate)

Other, please specify

3. This question covers a range of different activities related to the use of the VLE and other learning technologies. For each activity, please select the most appropriate statements (Please select all that apply, e.g. 'I have experience of this' AND 'I would like to learn more')

\begin{tabular}{|c|c|c|c|}
\hline I disagree with this & $\begin{array}{l}\text { Never heard } \\
\text { of this }\end{array}$ & $\begin{array}{l}\text { I would like } \\
\text { to learn } \\
\text { more } \\
\text { about this }\end{array}$ & $\begin{array}{l}\text { I have } \\
\text { experience } \\
\text { with this }\end{array}$ \\
\hline $\begin{array}{l}\text { Use of the VLE to provide } \\
\text { support information }\end{array}$ & $\Gamma$ & $r$ & Q \\
\hline $\begin{array}{l}\text { Provision of lecture materials } \\
\text { (presentations, handouts, etc.) }\end{array}$ & & & C \\
\hline Linking to external sites & C & 7 & Q \\
\hline Online submission tools & Q & Q & Q \\
\hline Online marking/feedback tools & 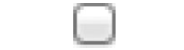 & Q & Q \\
\hline Wikis & U & U & Q \\
\hline
\end{tabular}




\begin{tabular}{|c|c|c|c|}
\hline I disagree with this & $\begin{array}{l}\text { Never heard } \\
\text { of this }\end{array}$ & $\begin{array}{l}\text { I would like } \\
\text { to learn } \\
\text { more } \\
\text { about this }\end{array}$ & $\begin{array}{l}\text { I have } \\
\text { experience } \\
\text { with this }\end{array}$ \\
\hline \multicolumn{4}{|l|}{$\mathrm{B} \log s$} \\
\hline \multicolumn{4}{|l|}{ Podcasting (audio only) } \\
\hline \multicolumn{4}{|l|}{$\begin{array}{l}\text { Screencasting } \\
\text { (voice-over ppt/screen) }\end{array}$} \\
\hline \multicolumn{4}{|l|}{$\begin{array}{l}\text { Developing your own } \\
\text { online video }\end{array}$} \\
\hline \multicolumn{4}{|l|}{ Online discussion forums } \\
\hline \multicolumn{4}{|l|}{ Mobile learning } \\
\hline \multicolumn{4}{|l|}{$\begin{array}{l}\text { Social networking in learning } \\
\text { and teaching, e.g. } \\
\text { Facebook/Twitter }\end{array}$} \\
\hline \multicolumn{4}{|l|}{$\begin{array}{l}\text { Developing interactive online } \\
\text { content }\end{array}$} \\
\hline \multicolumn{4}{|l|}{$\begin{array}{l}\text { Re-using existing materials } \\
\text { (that are suitably licensed) }\end{array}$} \\
\hline \multicolumn{4}{|l|}{$\begin{array}{l}\text { Use of apps \& mobile devices } \\
\text { (phones/tablets/etc.) }\end{array}$} \\
\hline \multicolumn{4}{|l|}{$\begin{array}{l}\text { Consciously dealing with } \\
\text { Copyright and Intellectual } \\
\text { Property Rights related } \\
\text { to teaching resources }\end{array}$} \\
\hline Other not listed & U & Q & Q \\
\hline
\end{tabular}

4. What barriers/challenges, if any, currently stop you from innovating with technology in your teaching?

$\square$ Lack of time to innovate in teaching

No reward structures for innovation in teaching

Priorities lie elsewhere, e.g. research

Lack of skills/literacy to innovate

Lack of support/training opportunities

Lack of motivation to innovate

Other, please specify

5. If you identified any barriers in Q4, are there any interventions that would enable you to overcome these barriers?

6. Please feel free to leave any additional comments related specifically to the use of VITAL and any minimum standards.

\section{Section 2: Online Submission \& Feedback}

Cost and efficiency savings such as reduced travel and student printing are key drivers for online submission. This section attempts to gauge opinions and experiences related to online submission and marking.

7. Have you ever encouraged students to submit coursework online?

No, I have not encouraged online submission 
I don't want to do this

I have encouraged online submission (alongside a printed hard copy)

Yes, I have encouraged online submission

Other, please specify

8. If you have used online submission tools already, can you please state whether you found the experiences positive or negative

Negative

Positive

9. Have you ever provided feedback electronically?

Yes

No

10. If you answered 'Yes' to Q9, can you please select the relevant statements against the following areas (Please select all that apply)

\begin{tabular}{|c|c|c|c|c|}
\hline & $\begin{array}{l}\text { I have } \\
\text { experience } \\
\text { with this }\end{array}$ & $\begin{array}{l}\text { I would like } \\
\text { to learn } \\
\text { more } \\
\text { about this }\end{array}$ & $\begin{array}{l}\text { Never } \\
\text { heard } \\
\text { of this }\end{array}$ & $\begin{array}{l}\text { I disagree } \\
\text { with this }\end{array}$ \\
\hline $\begin{array}{l}\text { I have used Microsoft Word } \\
\text { ('track changes' feature) } \\
\text { to provide feedback }\end{array}$ & Q & $\square$ & C & \\
\hline $\begin{array}{l}\text { I have used Turnitin/ } \\
\text { Grademark to } \\
\text { provide feedback }\end{array}$ & C & $\square$ & Q & Q \\
\hline I have used audio feedback & $\checkmark$ & $\square$ & Q & $\checkmark$ \\
\hline $\begin{array}{l}\text { I have used video to provide } \\
\text { feedback, e.g. recorded } \\
\text { screencasts (screen recording) } \\
\text { to provide feedback }\end{array}$ & Q & Q & Q & L \\
\hline $\begin{array}{l}\text { I have used other solutions } \\
\text { to provide electronic feedback }\end{array}$ & & Q & 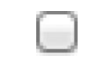 & $r$ \\
\hline
\end{tabular}

11. If you have used other systems to provide electronic feedback, please detail them here:

12. If you were to use any system for enabling learners to submit work online AND/OR mark work electronically, what system features and workflows would you expect?

13. Please feel free to leave any additional comments related specifically to online submission/ marking/feedback

\section{Section 3: Recording lectures}

Recording lectures can provide additional flexibility for learners. Research suggests the recording of lectures is primarily used by learners to prepare for summative assessments, as well as revisit materials to clarify understanding and overcome language barriers. Whilst some students will use recordings to catch up on missed classes, a number of authors suggest recorded lectures do not impact upon class attendance. This section aims to capture your experience and views on providing recorded lectures to learners

14. In relation to recording materials for learners, please select the relevant statements against the following activities (Please select all that apply) 


$\begin{array}{cccc}\begin{array}{c}\text { I would like } \\ \text { to learn } \\ \text { more }\end{array} & \begin{array}{c}\text { Never heard } \\ \text { of this }\end{array} & \begin{array}{c}\text { I disagree } \\ \text { with this }\end{array} & \begin{array}{c}\text { I have } \\ \text { with this }\end{array} \\ \text { about this } & \text { withen }\end{array}$

Provision of 'full' live lecture capture, e.g. video of speaker synchronised with slides

Provision of live recorded audio files alone

Pre-recorded audio

Pre-recorded video, e.g. interviews

Using pre-recorded audio/video specifically to 'Flip the Classroom', i.e. free up class time for 'other' activities, e.g. group work, interaction, etc.

Provision of audio synchronised with slides (screencasts)
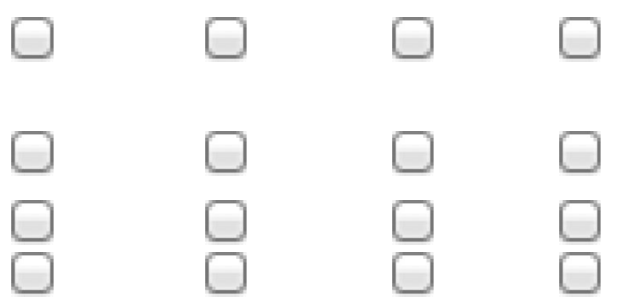

15. Which of the following drivers would encourage you to provide recorded materials?

To increase flexibility of learning, e.g., pace and place of content review

To overcome challenges of available space

To support assessment preparation

Overcome language barriers

To create a blend of face-to-face and online sessions

Develop independent learning

Overcome challenges related to note-taking

Overcome challenges related to sustaining concentration

Efficient/effective way to communicate complex information

Support for students with Specific Learning Difficulties e.g. dyslexia

Other, please specify

16. Which of the following barriers would discourage you from providing recorded materials?

Lack of time

Disagree with the concept

Students won't attend class

Students won't pay attention during class

Other, please specify

17. If you were to use any system for recording materials for learners (pre-recorded or live), what system features and workflows would you expect?

18. Please feel free to leave any additional comments related specifically to the recording of lectures

Summary

19. Please use this space if you have any general comments related to the use of technology in learning, teaching and assessment. 
20. If you would like to be involved in discussions related to the strategic implementation of technology in learning and teaching, please leave your name and email address here.

N.B. This will not be used in conjunction with any of your responses to earlier questions.

21. Finally, to help us identify themes and requirements from the varying contexts across the Faculty, please identify your area of employment.

School of Dentistry

School of Medicine

School of Health Sciences

School of Psychology

School of Veterinary Science

Centre for Excellence in Evidence-Based Learning \& Teaching (CEEBLT)

Human Anatomy Resource Centre (HARC)

Institute of Ageing \& Chronic Disease

Institute of Infection \& Global Health

Institute of Integrative Biology

Institute of Psychology, Health \& Society

Institute of Translational Medicine

Other, please specify 